\title{
O novo museu e a sociedade da informação
}

Mário Gouveia Junior

\begin{abstract}
Licenciado em História Universidade Federal de Pernambuco. Especialista em Cultura Pernambucana (FAFIRE).Mestrando em Ciência da Informção (UFPE)
\end{abstract}

http://dx.doi.org/10.1590/1981-5344/1632

Discute a emergência do novo museu e sua função enquanto abrigo do patrimônio e da memória nacional. Evidencia em que medida tais noções de preservação, celebração e ostentação do fantástico contribuíram no sentido de afastar o público dessas instituições. Identificase que essa forma de alienação acabaria por contribuir para a crise de valor e significados sociais do museu em relação à sociedade. Da mesma forma, verifica-se que o delineamento de uma transformação paradigmática começou a se apresentar a partir das discussões ocorridas na Mesa Redonda de Santiago, de 1972. Trata-se de uma investigação epistemológica que se respalda num estudo exploratório, no âmbito da Museologia e da Ciência da Informação. Como resultados, enfatiza-se que os museus evidenciam conceitos e práticas em metamorfose, estando focados na promoção da cidadania, na valorização e preservação do patrimônio cultural e ambiental, na universalidade do acesso à informação e no intercâmbio interinstitucional.

Palavras-chave: Novo Museu; Mesa Redonda de Santiago; Sociedade da Informação.

\section{The New Museum and the Information Society}

Discusses the emergence of the new museum and its function as custody the heritage and national memory. Highlights the extent to which such notions of preservation, celebration and pageantry of fantastic contributed towards the public away from these institutions. This disposition would eventually contribute 
to the crisis of value and social meanings of the museum in relation to society. Likewise, it appears that the design of a paradigmatic transformation began performing from the discussions that took place in Santiago Round Table, 1972. This is an epistemological investigation that supports an exploratory study in the context of Museology and Information Science. As a result, it is emphasized that museums demonstrate concepts and practices in metamorphosis and it is focused on promoting citizenship in the appreciation and preservation of cultural and environmental heritage, in universal access to information and inter-institutional exchange.

Keywords: Mesa Redonda de Santiago; New Museum; Information Society.

Recebido em24.10.2013 Aceito em 23.11.2014

\section{Introdução}

Entende-se a Ciência da Informação - para além de suas variadas, e até contraditórias, definições e classificações - como um campo de estudos que promove o desenvolvimento do homem em sociedade, apresentando-Ihe possibilidades de intervenção na realidade através de ações sociais (HABERMAS, 1989).

É bem verdade que a construção de propostas para a formulação de um projeto social baseado numa política de informação pautada na democratização do acesso aos conteúdos informacionais ainda representa um desafio. Isso porque o compartilhamento da informação, em larga medida, é tributário do protagonismo dos cidadãos no espaço público no sentido de transformar o manancial de informação disponível em conhecimento crítico, partilhado com sua comunidade e capaz de libertar e transformar outros sujeitos.

Nessa perspectiva, por sinal, pode-se identificar pontos de contato entre a Ciência da Informação voltada para conteúdos sócioinformacionais e o pensamento de Paulo Freire acerca da importância da assunção do protagonismo dos sujeitos nos processos educacionais. Encontra-se, ainda, nas desejáveis autonomia e criticidade, elementoschave para a concretização do ato de estudar enquanto atitude frente ao mundo (FREIRE, 2011).

As práticas informacionais, pensadas como um processo resultante de uma ação socialmente partilhada através de criticidade e autonomia, são constituídas mediante produção, transferência, aquisição e significação por parte dos sujeitos, deixando de se apresentarem meramente como veículo das ideologias. Isso porque, tal como a informação, a memória pode atuar como instrumento de dominação e domesticação dos homens, mas também denota a possibilidade de se 
constituir em ferramenta imprescindível à sua libertação, conforme destaca Le Goff (2003).

Um estudo mais pormenorizado acerca de um conceito de autonomia, pode levar à compreensão de que esta, sob a ótica de Castoriadis (1992), seria o agir reflexivo individual e social de uma razão, criado num movimento incessante. É ainda um projeto, tanto no plano ontológico quanto no plano político, que visa ao nascimento do poder instituinte entre os sujeitos ao mesmo tempo em que evidencia um "monumento de criação, que inaugura não só outro tipo de sociedade, mas também outro tipo de indivíduos" (CASTORIADIS, 1992, p.139).

Tais indivíduos, uma vez dotados de autonomia, têm o poder de superar a alienação e alcançar o desenvolvimento social. É justamente na defesa dessa proposta de construção coletiva da memória informacional que, via de regra, os museus se apresentam atualmente.

No entanto durante muito tempo não apenas os museus, como bibliotecas e arquivos existiram de acordo com uma lógica alicerçada em ideais de sacralização e preservação que afastavam eventuais usuários. Esse paradigma preservacionista, sua gênese, voga e colapso, bem como as possibilidades de transformação - discutidas desde a Mesa Redonda de Santiago, de 1972 - serão apresentados a seguir.

\section{0 poder simbólico dos lugares de memória}

Aqueles que controlam os canais de informação, e que se dispõem, de acordo com seus interesses, a construir mitos e editar "a verdade", manipulando-a, são os detentores do que Pierre Bourdieu chamou de poder simbólico - forma de domínio invisível exercido, em parte, a expensas da aquiescência, cumplicidade e submissão da maioria (BOURDIEU, 1989).

O chamado poder simbólico conta, ainda, com a ideia de que "a adaptação a uma posição dominada implica uma forma de aceitação da dominação" (BOURDIEU, 2011, p.360). Evidencia-se, dessa forma, um poder que semeia e promove memórias e esquecimentos, relacionados dialogicamente (CHAGAS, 2002).

Ainda em relação ao poder e às suas formas de imposição e aceitabilidade, não se pode, contudo, perder de vista a ideia foucaultiana de que o poder não existe enquanto instituição ou estrutura; seria, antes, o nome conferido a uma situação estratégica complexa em uma sociedade específica (FOUCAULT, 2006).

Segundo Marshall McLuhan (1977) quando o homem caminhou da oralidade para a escrita, a assimilação e interiorização dessa nova tecnologia, que representou o alfabeto fonético, transladaram o homem do mundo mágico da audição para o mundo neutro da visão. Com o advento da escrita e a posterior invenção de Gutenberg, aqueles que dominavam essa tecnologia, para além de comunicarem suas ideias através de signos visuais, também poderiam produzir um registro perene destes signos e sinais, e, dessa forma criar uma memória exterior à própria mente (McGARRY, 1999). Essa demanda se faria necessária à 
medida que a quantidade de informação se tornasse superior à capacidade humana de guardá-las todas na memória.

Seria preciso, então, solucionar o problema do armazenamento de informações em suportes palpáveis e duráveis (LE COADIC, 2004). É assim que a arte da memória, oriunda de uma tradição muito antiga, seria subjugada pelos excessos de papel, e, a posteriori, dos bancos de dados e da internet, que a tornaram supérflua e inútil (ROSSI, 2010). Surgiriam, assim, o que Leibniz chamaria de memórias de papel e a necessidade por lugares de memória (NORA, 1993).

Um dos principais objetivos da Ilustração era fazer do livro uma ferramenta de transformação da sociedade, modelando hábitos através de sua leitura, seja ela verbal ou icônica, e ditando a substituição das leis consuetudinárias (CERTEAU, 2008). Esse progresso da memória escrita pretendido pelos iluministas foi contemporâneo à criação dos primeiros museus etnográficos responsáveis pelo registro, coleção, conservação, transmissão, estudo e interpretação de objetos materiais. É nessa perspectiva que:

aos poucos, os museus etnológicos transformaram-se em depósitos ordenados de uma cultura material fetichizada e submetida a uma lógica evolutiva. Comparar e classificar se tornaram as metas desses cientistas, verdadeiros 'filósofos viajantes', que financiados por instituições científicas dirigemse a terras distantes em busca de coleções que representem variedades da flora, fauna e da contribuição humana na terra (SCHWARCZ, 1993, p.69).

As últimas décadas do século XIX marcam o momento histórico em que o homem se dedicou às invenções das tradições em massa; as invenções oficiais de ordem política trataram de dar conta das profundas e rápidas transformações sociais da época. Exemplos disso, na França, foram as instituições educacionais laicas, a invenção de cerimônias públicas e a produção em massa - numa proporção maior do que aquela verificada nos anos imediatamente subsequentes à Revolução de 1789 de monumentos públicos (RIBEIRO, 1998)

De acordo com Pierre Nora (1993), graças ao volume de informação produzido espontaneamente pela sociedade, seus meios técnicos de reprodução e de conservação, e, sobretudo, à superstição e ao respeito ao vestígio, vive-se na época que mais produziu arquivos. Isso porque à medida que a memória tradicional desaparece, as sociedades são forçadas a acumular sinais visíveis do que foi, criando ambientes artificiais, que abrigariam imagens cuja função seria a de "[...] trazer algumas coisas à memória" (ROSSI, 2010, p.23).

Foi assim que arquivos, bibliotecas e museus se fizeram cada vez mais necessários; porque, conforme nos ensina Pierre Nora (1993), o homem coletivo não habita mais a própria memória; por isso a necessidade de lhe consagrar espaços de produção e divulgação que se enraízam no concreto, no gesto, na imagem, no objeto, materializando-a. Esses redutos da memória representam os rituais sagrados de uma 
sociedade desritualizada e dessacralizada, que só é capaz de lembrar uma ínfima parcela daquilo que poderia ter necessidade de lembrar.

Esta é uma sociedade que precisava de suportes exteriores e referências tangíveis que pudessem parar o tempo, bloqueando a ação do esquecimento, imortalizando a morte, materializando o imaterial e prendendo o máximo de sentido num mínimo de sinais (NORA, 1993, p.22). Todavia era essa ainda uma memória oficial, digna dos templos e das sacralizações de objetos - sobretudo nas bibliotecas e museus - das ações e concepções focadas na salvaguarda e na relação mais hostil possível com os usuários-visitantes.

\section{Os museus modernos: do sagrado ao silêncio e a crise}

Concebidos mediante a perspectiva de conservação e legitimação da hegemonia de um grupo que se sobrepunha política, econômica e socialmente à maioria, os museus apresentam-se enquanto espaços celebrativos de uma memória oficial (CHAGAS, 2009). Esse marco temporal coincide com o pós-1789 e suas medidas de conservação do patrimônio histórico na França - fundamentais para que se barrassem certos movimentos de iconoclastia, por vezes, sugeridos quando triunfa uma revolução (CHOAY, 2006).

De acordo com essa ótica preservacionista de tudo guardar, todos os objetos ali encerrados parecem conter um sentido não mais ligado à sua função, já que passaram a denotar um valor consagrado de memória, de relato histórico (JEUDY, 1990). Nesse particular, destituídos de utilidade, os referidos objetos passam a se apresentar como semióforos, posto que representam o invisível e são dotados de um significado. Apesar de não serem manipulados, encontram-se expostos ao olhar. É justamente nesse momento que o semióforo desvela o seu significado, tornando-se uma peça de celebração. Nesse caso, quanto mais carga de significado tem um objeto, menos utilidade tem, e vice-versa (POMIAN, 1984).

Os espaços que guardavam tais objetos, os chamados lugares de memória (NORA, 1993), apesar de serem, em geral, de natureza pública, denotaram durante muito tempo suas inclinações pouco democráticas, onde os objetos não guardavam relações com 0 documento ou a perspectiva dos grupos sociais, mas com o monumento e o que Mário Chagas (2009) chamou de coágulos de poder.

As instituições de memória, então, deveriam ser regidas como um mecanismo de poder disciplinar que agia no sentido de provocar lembranças e esquecimentos, de condicionar o olhar e aprisionar o entendimento no tocante às ciências e às artes (CHAGAS, 2002). Ademais, o consumo e a valorização das obras de arte contidas nos museus não eram entendidos como possíveis para todos os homens indistintamente. Isso porque, nas sociedades pós-industriais, marcada pelas relações de trabalho, capital e mais-valia, todos eram iguais, mas uns eram mais iguais que outros (ORWELL, 2003). 
É justamente no tocante à prática cultural, à competência artística e às atitudes em relação às obras culturais no sentido de consumi-las e valorizá-las que está associada a noção de capital cultural (BOURDIEU, 2007). Esta, conforme nos ensina Pierre Bourdieu (2001), surge da necessidade de compreensão das disparidades de desempenho escolar dos indivíduos provenientes de distintos grupos sociais.

O capital cultural pode existir sob três formas: como incorporado, como objetivado e como institucionalizado. O capital cultural incorporado tem como elementos constitutivos os gostos e hábitos dos indivíduos, geralmente, inculcados por seu background familiar. Este, diga-se de passagem, contribui no sentido de facilitar o aprendizado dos conteúdos e dos códigos escolares (BOURDIEU, 2001, 2011).

O capital cultural objetivado configura-se sob a forma de bens culturais - esculturas, pinturas e livros - cuja aquisição depende apenas da compra desses bens. No entanto a sua apropriação simbólica só se processará se o indivíduo possuir os códigos para decifrá-los, sendo necessário 0 capital cultural incorporado. 0 capital cultural institucionalizado, por seu turno, evidencia-se através de atestados, certificados, títulos e diplomas escolares (BOURDIEU, 2001).

A partir de tais conceitos, pode-se inferir que as instituições de educação formal - e mesmo os espaços de educação não formais, como, por exemplo, os museus - que se dispõem à mera reprodução do sistema social, contribuem para o entendimento de que o capital cultural do indivíduo, e, por conseguinte, o seu ulterior sucesso profissional, depende dos gostos e hábitos que este recebeu de sua família.

A escola e a sociedade que corroboram com essa linha de pensamento, agem no sentido de ignorar, e mesmo suprimir, as possibilidades de transformação e desenvolvimento social que uma educação autônoma, crítica, reflexiva e libertadora pode fomentar nos sujeitos (FREIRE, 2002). Foi justamente a partir desses esforços de manutenção do status quo, que o Estado e as classes dominantes forjaram redutos museais, patrimoniais e custodialistas (SILVA; RIBEIRO, 2011) que se distanciaram da sociedade e de suas funções sociais em prol do desenvolvimento.

Ao confeccionar um breve estudo mito-genealógico sobre as origens do museu - filho de Apolo e Calíope e descendente de Zeus e Mnemósine -, Mário Chagas (2002) considerou-o como estritamente ligado à poesia e à música; e, por conseguinte, como elemento que transcende a escrita e a memória por ser capaz de despertar em seus espectadores sentimentos de estupefação, admiração e assombro.

Em sua perspectiva, inspirada por Francis Bacon, esse assombro seria o item provocador do conhecimento, posto que aquilo que chama a atenção pode gerar uma problematização cuja busca por respostas, nem sempre encontradas, fomenta o conhecimento. Desse modo, um dos papeis do museu seria o de fornecer subsídios para que fosse gerada a curiosidade epistemológica de que trata Paulo Freire (2002). Contudo não se ignora o fato de que os primeiros museus contemporâneos foram concebidos em torno dos interesses dos governantes, dos grandes, dos 
vitoriosos e dos heróis, evidenciando-se, nessa época, a "explosão do espírito comemorativo" (SCHWARCZ, 1993, p.68).

Esses lugares, por guardarem estreita relação com narrativas mitológicas e artefatos valiosos, durante muito tempo eram concebidos e dispostos de modo a afastar o homem simples. Nesse caso, admiração ou assombro não contribuem de modo a aproximar e causar interesse; pelo contrário, o fantástico, por não dialogar com a realidade de um eventual público, o repele, obscurecendo a função de ser do Novo Museu e suas propostas enquanto espaço criador de meios de desenvolvimento social.

É assim que se defende a ideia de que se não há ponte entre o objeto que se expõe e o seu sujeito - o público - não está sendo processada a transformação inerente ao ato reflexivo de educar-se (FREIRE, 2002). Nesse momento, parece relevante considerarmos que a dimensão sociocultural e patrimonial dos museus tornou-se tema de grande interesse no século XX para todos os gestores e guardiões de um saber memorial que se via diante de uma real ameaça de extinção.

Diante dessa lógica de pensamento, que envolve perigo e valor, o patrimônio se aloja entre a preservação e a posse material, espiritual, econômica ou simbólica (CHAGAS, 2005). Note-se, nessa perspectiva, que as noções de guarda ou posse - que se destina àquilo que tem um valor econômico, simbólico ou afetivo, no intuito de evitar o seu esquecimento ou desaparecimento - fazem parte do que Armando Malheiro da Silva e Fernanda Ribeiro (2011) chamam de paradigma custodial patrimonialista, historicista e tecnicista. Esse modelo funcionou - e, em alguns redutos, ainda funciona - a partir de um quase desejo de afastamento de eventuais usuários-visitantes, entendidos como verdadeiros inimigos da ordem e provocadores de uma indesejada entropia nos sistemas.

Tal sentimento de aversão ou incômodo em relação aos espaços museais é bem ilustrado tanto pelas considerações do poeta e escritor Paul Valéry (1960) acerca do problema e das proibições dos museus, por ele chamados de casas da incoerência, quanto pela ótica de Adorno (1998), que enxergava esses espaços de preservação patrimonial conectados com o mausoléu para além da fonética, uma vez que em sua antropofagia preservacionista, os museus, ao sacralizarem objetos, atentavam contra sua vida.

Acrescente-se que Valéry e Adorno escreveram e pensaram sobre as sociedades europeias na primeira metade do século XX. Nessa época, os conceitos e discursos em relação ao patrimônio cultural ainda compreendiam os monumentos destinados a conservar a memória e combater o desaparecimento ou mesmo o esquecimento das glórias da nação e de seus heróis.

No caso brasileiro, as atenções nesse campo se voltavam oficialmente a partir do Decreto-Lei no 25, de 30 de novembro de 1937, através do qual o patrimônio histórico e artístico nacional era definido como:

[...] o conjunto de bens móveis e imóveis existentes no país e cuja conservação seja de interesse público, quer por sua 
vinculação a fatos memoráveis da história do Brasil, quer por seu excepcional valor arqueológico ou etnográfico, bibliográfico ou artístico (BRASIL, 1937).

Assim, o patrimônio cultural - percebido apenas na esfera do tangível, posto que saberes e práticas ainda não eram considerados estava inevitavelmente associado à história oficial e a tudo aquilo que o Estado entendesse como valor a ser difundido e preservado. Deve-se, por outro lado, enfatizar que determinado objeto, uma vez elevado à condição de bem patrimonial, tornava-se artigo de mera contemplação, isto é, suas funções e utilidades perdiam-se tal como seu lugar se modificava (POMIAN, 1984).

É desse modo que os museus se apresentavam como novos templos da morte, a engendrar efeitos de projeção que modificam incessantemente as formas da percepção estética e da apreensão efetiva (JEUDY, 1990). Numa palavra, a espada já não é mais manuseada para atividades militares, assim como a cadeira não serve mais para repousar o corpo ou a pena já não ratifica mais nenhuma lei importante; encerrados nos museus, os objetos são salvaguardados, sacralizados, enterrados nos mausoléus da memória oficial.

Em relação ao acúmulo de objetos em torno da gênese do museu moderno, percebe-se a ausência de relação, de dinâmica social na construção e gestão do patrimônio cultural, de responsabilidade de um Estado ainda dotado de uma visão tecnicista.

O próprio Estado, diga-se de passagem, criou um sem-número de leis de conservação que evidenciaram o ritmo da sacralização cultural dos objetos, signos e lugares alusivos às culturas dominantes (JEUDY, 1990).

É dessa forma que as instituições museais legitimariam uma memória oficial sustentada pela informação/objeto museológico aplicada aos interesses das ideologias das classes dominantes e favorecendo a consolidação da hegemonia do aparelho do Estado através da alienação dos sujeitos de seus direitos, vontades, interesses e necessidades. Alienação esta que não poderia fomentar outro sentimento na sociedade que não o do afastamento, da indiferença.

A interiorização e a intensificação desse sentimento, nos trinta anos seguintes, parece ter contribuído decisivamente para a configuração da crise nos espaços museais não só no Brasil, mas em toda a América Latina, conforme será abordado na sequência. Antes disso, todavia, cabem algumas considerações no tocante às ideias de paradigma, crise e mudança de paradigma.

\section{O Novo Museu e a Sociedade da Informação}

As instituições de memória, ao denotarem suas características pautadas na celebração do poder e na exclusão do popular vigoraram desde a época da organização e institucionalização dos primeiros espaços museais (SCHWARCZ, 1993). Os primeiros sinais de esgotamento deste modelo começaram a ser percebidos em meados do século $X X$, quando se 
começou a perceber, para além da ausência de público nos museus, sobretudo na América Latina, profundas crises nos campos da política, economia e cultura desses países (ICOM, 1972).

Esse estado de coisas disseminara a idéia de que tais espaços não evidenciavam importância nem necessidade. E nesse particular, parece pertinente a ideia de que "aquilo de que não [se] tem necessidade é igualmente desprovido de valor enquanto não for usado para adquirir alguma coisa de que necessite" (FOUCAULT, 2007, p.263). Numa palavra, o valor não pode ser formado a partir da produção, mas do seu consumo.

Em virtude de tais constatações, realizou-se, em 1972, uma conferência do Conselho Internacional de Museus, em Santiago, no Chile, onde se deliberou acerca do papel decisivo, que caberia aos museus, no tocante à educação das comunidades. Ficou decidido também que àqueles competiria a missão de tornar suas coleções acessíveis ao máximo, tanto a pesquisadores qualificados quanto a entidades públicas, privadas e religiosas.

O museu foi definido, ainda, como uma instituição a serviço da sociedade no sentido de participar da formação de sua consciência sem isentar o protagonismo das comunidades nessa ação (ICOM, 1972). Doze anos mais tarde, o ICOM, reunido no Canadá, através da Declaração de Quebec, ratificaria as deliberações feitas em Santiago (ICOM, 1984).

Em 1992, no ano em que se celebrou os vinte anos da confecção da Declaração de Santiago, discutiu-se, em Caracas, na Venezuela, entre outros aspectos, a confirmação da vigência dos postulados feitos em Santiago; uma reflexão sobre a ação social do museu e a necessidade da tomada de consciência dos poderes públicos acerca da importância da inserção de políticas museológicas no campo da cultura.

Nesse mesmo evento discutiram-se as crises políticas, econômicas e culturais que se intensificavam por quase toda a América Latina entre fins dos anos 1980 e começos de 1990; e o museu não apenas como fonte de informação ou instrumento de educação, mas, fundamentalmente, como um espaço adequado onde a comunidade pudesse se expressar e interagir com os processos e produtos culturais, fomentando, assim, um desenvolvimento equilibrado e um maior bem-estar coletivo (ICOM, 1992).

Registre-se ainda que nas três conferências mencionadas tomaram parte representantes da Argentina, da Bolívia, do Brasil, do Chile, da Colômbia, de Cuba, do Equador, do México, da Nicarágua, do Peru e da Venezuela. Portanto, apenas países latinoamericanos, que buscavam, através de novos paradigmas, soluções para problemas e crises que se Ihes apresentavam à época. É desse modo que, em fins do século $X X$, diante de algumas crises e adversidades pelas quais o museu passou em relação à sua funcionalidade e concessão de significado e valor para o usuário, um grupo de especialistas, a partir de 1972, se reuniu para traçar uma mudança de paradigma para a Museologia e para o próprio museu.

Para que as instituições museais pudessem se manter vivas e superarem suas próprias crises, precisaram aceitar-se como espaços de (re)invenção, de interatividade, de ludicidade, de franco convite à 
sociedade como um todo. O seu foco, por sinal, transferiu-se do objeto/documento/monumento para o usuários-visitantes - agora vistos como protagonistas nos processos museais de produção e disseminação de cultura, memória e informação. Nesse particular, tal como nos arquivos e nas bibliotecas, o museu tem agido no sentido de substituir o paradigma custodial, patrimonialista, historicista e tecnicista pelo paradigma póscustodial, informacional e científico (SILVA; RIBEIRO, 2011). Atende-se, assim, à ideia de que toda biblioteca, assim como todo museu, carrega uma concepção implícita de cultura, saber e memória, mas só adquire sentido pelo trabalho de seus leitores, por suas demandas.

Essas novas demandas para os museus só vêm beneficiar e facilitar - cumprimento da pauta da Sociedade da Informação: o compartilhamento de informação. E nesse sentido, o museu, como a biblioteca, se apresenta enquanto um organismo em crescimento, que se deve apresentar como um espaço privilegiado para produção e reprodução do conhecimento. Mostra-se, também, como um espaço dinâmico, de vida, de reinvenção e de recriação de cultura, memória e informação. Um organismo calcado na valorização da dignidade humana, na promoção da cidadania, no cumprimento da função social, na valorização e preservação do patrimônio cultural e ambiental, na universalização de seu acesso, no respeito e valorização da diversidade cultural e no intercâmbio institucional (BRASIL, 2009).

\section{Considerações finais}

É nos museus que os bens culturais móveis - vulneráveis à ação do tempo e ao esquecimento da sociedade - são cuidados, estudados, exibidos e apreciados pelo público a partir de um olhar sempre novo, fundamentado na missão de democratizar o acesso à cultura para construção de uma sociedade mais atuante.

Vale lembrar, nesse sentido, que além de apreciar os acervos museológicos, os usuários-visitantes dos museus têm, cada vez mais, a possibilidade de interagir com as peças em exposição, ressignificando sua cultura e sua memória, enquanto sujeitos dessa ação. Nesse contexto, negando-se à tarefa de depósito de documentos produzidos pelo homem em sociedade, o museu de apresenta como uma instituição aberta ao público, a serviço da sociedade e de seu desenvolvimento mediante um trabalho permanente com a preservação e divulgação do patrimônio cultural, representado em seus acervos e exposições.

Dispõe-se, ainda, o museu a fomentar e ampliar as possibilidades de construção identitária e coletiva, a produção de conhecimentos, as oportunidades de lazer e a inclusão social, através da democratização do acesso, uso e produção de bens culturais em seus espaços, sejam eles físicos ou virtuais. Os museus são apontados também como instituições sem fins lucrativos que conservam, investigam, comunicam, interpretam e expõem, para fins de preservação, estudo, pesquisa, educação, contemplação e turismo, conjuntos e coleções de valor histórico, artístico, 
científico, técnico ou de qualquer outra natureza cultural, abertas ao público, a serviço da sociedade e de seu desenvolvimento.

São instituições de memória que têm como princípios a valorização da dignidade dos sujeitos, a promoção da cidadania, o cumprimento da função social, a valorização e preservação do patrimônio cultural e ambiental, a universalidade do acesso, o respeito e a valorização à diversidade cultural e o intercâmbio interinstitucional. Numa palavra, os museus evidenciam conceitos e práticas em metamorfose, devendo ser percebidos como instituições de memória interiorizadas pelos indivíduos e dispostas de modo a facilitar ao máximo o acesso, a autonomia individual e as possibilidades de participação efetiva em todo poder explícito existente na sociedade.

No entanto, apesar de muitas mudanças terem se configurado nos ambientes museais e em seus discursos no que concerne suas relações com os usuários-visitantes e seu papel no processo de diálogos e negociações, identificam-se algumas permanências. Algo que denuncia a ideia de que a mudança de paradigma não se processa mediante quebra de um modelo antigo, e sua total recusa, para a inserção de um novo modelo, aceitado plenamente.

Há que se perceber a vigência simultânea de paradigmas como fato corriqueiro em diversos campos da ciência e mesmo das relações sociais. Nesse sentido, tratando diretamente das temáticas abordadas neste trabalho, pode-se salientar que preservação de informação museal e acessibilidade aos conteúdos preservados podem representar essa ideia de simultaneidade de práticas. O que parece realmente fundamental é que a sociedade da informação entenda e assuma o importante papel que deve representar: o de se configurar enquanto boa ancestral.

\section{Referências}

ADORNO, Theodor W. Prismas: Crítica Cultural e Sociedade. São Paulo: Ática, 1998.

BOURDIEU, Pierre. O poder simbólico. Rio de Janeiro: Bertrand, 1989.

BOURDIEU, Pierre. Os três estados do capital cultural. In: NOGUEIRA, Maria Alice; CATANI, Afrânio. (org.) Escritos de Educação. 3. ed. Petrópolis: Vozes, 2001.

BOURDIEU, Pierre; DARBEL, Alain. O amor pela arte: os museus de arte na Europa e seu público. 2.ed. São Paulo / Porto Alegre: Zouk, 2007.

BOURDIEU, Pierre. A distinção: crítica social do julgamento. 2.ed.rev. Porto Alegre: Zouk, 2011.

BRASIL. Decreto-Lei n. 25, de 30 de novembro de 1937. Disponível em: https://www.planalto.gov.br/ccivil 03/decreto-lei//Del0025.htm. Acesso em: 12 ago. 2011. 
BRASIL. Lei n. 11.904, de 14 de janeiro de 2009. Disponível em: https://www.planalto.gov.br/ccivil 03/ ato2007-2010/2009/lei/l11904.htm. Acesso em: 20 dez. 2011.

CASTORIADIS, Cornelius. Poder, política, autonomia. In: CASTORIADIS, Cornelius. O mundo fragmentado (As encruzilhadas do labirinto / 3). Rio de Janeiro: Paz e Terra, 1992.

CERTEAU, Michel de. A invenção do cotidiano: 1. Artes de fazer. 15.ed. Petrópolis: Vozes, 2008.

CHAGAS, Mário de Souza. Memória e poder: dois movimentos. In: CHAGAS, Mário de Souza; SANTOS, Myrian Sepúlveda dos. Museu e Políticas de Memória. Cadernos de sociomuseologia. v.19. nº.19, Universidade Lusófona de Humanidades e Tecnologias (ULHT), Lisboa, 2002.

CHAGAS, Mário de Souza. Casas e portas da memória e do patrimônio. In: GONDAR, Jô; DOBEDEI, Vera Lúcia (Organizadores). O que é memória social? Rio de Janeiro: Contra Capa Livraria / Programa de Pós-Graduação em Memória Social da Universidade Federal do Estado do Rio de Janeiro, 2005.

CHAGAS, Mário de Souza; NASCIMENTO JUNIOR, José do (org.). Subsídios para a criação dos Museus Municipais. Rio de Janeiro: Ministério da Cultura/Instituto Brasileiro de Museus e Centros Culturais/Departamento de Processos Museais, 2009.

CHOAY, Françoise. A alegoria do patrimônio. 3.ed. São Paulo: UNESP, 2006.

FOUCAULT, Michel. Microfísica do poder. 22.ed. Rio de Janeiro: Graal, 2006.

FOUCAULT, Michel. As palavras e as coisas: uma arqueologia das ciências humanas. 9.ed. São Paulo: Martins Fontes, 2007.

FREIRE, Paulo. Pedagogia da autonomia: saberes necessários à prática educativa. 24.ed. São Paulo: Paz e Terra, 2002.

FREIRE, Paulo. Ação cultural para a liberdade e outros escritos. 14.ed.rev.atual. Rio de Janeiro: Paz e Terra, 2011.

HABERMAS, J. Consciência moral e agir comunicativo. Rio de Janeiro: Tempo Brasileiro, 1989.

ICOM (Conselho Internacional de Museus). Declaração de Santiago. MesaRedonda de Santiago do Chile, 1972.

ICOM (Conselho Internacional de Museus). Declaração de Quebec Princípios de Base de uma Nova Museologia 1984. Quebec, 1984.

ICOM (Conselho Internacional de Museus). Declaração de Caracas. Caracas, 1992. 
JEUDY, Henri-Pierre. Memórias do social. tradução de Márcia Cavalcanti. Rio de Janeiro: Forense Universitária, 1990.

LE COADIC, Yves-Fraçois. A Ciência da Informação. 2.ed.rev. e atual. Brasília: Briquet de Lemos, 2004.

LE GOFF, Jacques. História e memória. 5.ed. Campinas: UNICAMP, 2003.

McGARRY, Kevin. O contexto dinâmico da informação. Brasília: Briquet de Lemos, 1999.

McLUHAN, Marshall. A galáxia de Gutenberg: a formação do homem tipográfico. São Paulo: Editora Nacional, 1977.

NORA, Pierre. Entre memória e história: a problemática dos lugares. In: PROJETO HISTÓRIA: Revista do Programa de Estudos Pós-Graduados em História e do Departamento de História da PUC-SP, n.10, p.7-28, São Paulo, 1993.

ORWELL, George. A revolução dos bichos. 2.ed. São Paulo: Globo, 2003.

POMIAN, Krzysztof. Colecção. In: Enciclopédia Einaudi. 1. Memória e História. Lisboa: Imprensa Nacional - Casa da Moeda, 1984, p.51-86. Disponível em: http://flanelografo.com.br/impermanencia/biblioteca/Pomian\%20\%281984b\%29.pdf Acesso em: 13 nov. 2012.

ROSSI, Paolo. O passado, a memória, o esquecimento: seis ensaios da história das ideias. São Paulo: UNESP, 2010.

RIBEIRO, Fernanda. O acesso à informação nos arquivos. Dissertação de Doutoramento em Arquivística apresentada à Faculdade de Letras da Universidade do Porto, 1998.

SCHWARCZ, Lilia Moritz. O espetáculo das raças: cientistas, instituições e questão racial no Brasil - 1870-1930. São Paulo: Companhia das Letras, 1993.

SILVA, Armando Malheiro da; RIBEIRO, Fernanda. Paradigmas, serviços e mediações em Ciência da Informação. Recife: Néctar, 2011.

VALÉRY, Paul. Le problème des musées. In: HYTIER, Jean (Ed.). Paul Valéry - Oeuvres II. Paris: Éditions Gallimard, 1960. 